\title{
EMPLOYMENT OF INDIRECT DOT-ELISA FOR THE DETECTION OF ANTI-PARAMPHISTOMUMEPICLITUM ANTIBODIES IN RUMINANTS
}

\author{
Syed Shabih Hassan \\ Department of Veterinary Parasitology, College of Veterinary Science \\ Guru Angad Dev Veterinary and Animal Sciences University, Ludhiana - 141004, Punjab, India
}

Research Paper

Received: 10.07.2020

Revised: 18.07.2020

Accepted: 29.07.2020

\begin{abstract}
Paramphistomosis is one of the major parasitic diseases causing heavy economic losses to livestock production. Diagnosis of disease in early stage is very important for minimizing the losses through effective treatment. The conventional methods of diagnosis such as detection of eggs in faeces by sedimentation and floatation techniques have limitations while modern serology based tests like enzyme linked immune-sorbent assay requires well equipped laboratory. The immature and adult Paramphistomumepiclitum were collected from rumen of slaughtered goat and buffaloes in slaughterhouses fromBareilly, Delhi, Dehradun and Ludhiana. Collected parasites were thoroughly washed in normal saline and processed separately for antigen preparation. Parasites were homogenized in $0.1 \mathrm{M} \mathrm{PBS} \mathrm{pH}=7.4$, sonicated in Soniprep-150 for 8 min (4 cycles of 2 min each) and centrifuged at $15000 \mathrm{rpm}$ for $15 \mathrm{~min}$ at 4C. The supernatant obtained was filtered through $0.22 \mathrm{~m}$ Millex-GV filter (Millipore, France) and stored in small aliquots of 0.5 $\mathrm{ml}$ each at -20C to be used as somatic antigen for ELISA test. Sera were collected at monthly interval from rabbits immunized by somatic P. epiclitum antigen for determining the titre variation with time and for Dot-ELISA tests. Indirect Dot-ELISA was standardized using antigen concentration ranging from $5 \mu \mathrm{g} / \mu \mathrm{l}-10 \mathrm{ng} / \mu \mathrm{l}$ and goat anti-rabbit HRPO conjugate dilutions. P. epiclitum antigen was used for coating nitro cellulose membrane (NCM) pad on combs for DotELISA and kept overnight at $4^{\circ} \mathrm{C}$. The combs were then incubated in $3 \%$ lactogen in $\mathrm{PBS}, \mathrm{pH}=7.4$, at $37^{\circ} \mathrm{C}$ for $1 \mathrm{hr}$ for blocking the non-specific antigen binding sites. Subsequently, the combs were incubated in rabbit anti-P. epiclitum sera in dilution range 1:50 - 1: 90000 at $37^{\circ} \mathrm{C}$ for $1 \mathrm{hr}$ followed by three washings in PBS of 2 min each. The combs were then incubated in goat anti-rabbit $\mathrm{HRPO}$ conjugate at $37^{\circ} \mathrm{C}$ for $1 \mathrm{hr}$ again followed by 4 washings in PBS of 2 min each. The combs were then incubated in substrate 3, 3'- Diamino-benzidine hydrochloride $\left(5 \mathrm{mg} / 10 \mathrm{ml}\right.$ PBS $+10 \mu \mathrm{l} 0.06 \% \mathrm{H}_{2} \mathrm{O}_{2}$ ) for 5- $15 \mathrm{~min}$. Development of dark brown spot indicated positive reaction after using various control. The optimum antigen concentration was found to be $100 \mathrm{ng} / \mu \mathrm{l}$ and optimum conjugate dilution was found to be $1: 500$. Anti-sera collected from rabbits at the interval of 30 and 60 days showed a maximum titre of 1:40,000.

The experimentally infected sheep sera were taken at weekly interval from four sheep, which were examined against adult somatic P. epiclitum antigen following concentrations 50-75 ng/ $\mu \mathrm{l}$ and conjugate dilution 1:500 to 1:1000 and sera dilution at 1:600 and 1:800. Sheep sera showed reaction after 2 weeks post infection. A total of 200 sera samples were examined by indirect Dot-ELISA. Overall percent positive incidence rate was recorded to be 33 percent. The highest percent positivity (38.66\%) was found in buffaloes followed by $31.7 \%$ in sheep, $26.66 \%$ in cattle and $25 \%$ in goats. In the present study, a rapid and simple test (Dot-ELISA) was developed for the diagnosis of paramphistomosis. The findings are helpful for detection of paramphistomum antibodies in naturally infected animals and can be used under field conditions.
\end{abstract}

Keywords: Detection, Indirect Dot-ELISA,Paramphistomumepiclitum, Antibodies, Ruminants.

\section{INTRODUCTION}

Parasites are the ideal biological models for the study of speciation. The parasites can adopt various means and methods to evade the immune system. Now a days

*Corresponding author: fish_ab@rediffmail.com 
transmission of parasitic diseases, its diagnosis and control have become a major concern throughout the world. Among the parasitic diseases, paramphistomosis is one of the most pathogenic disease in domesticated animals causing heavy economic losses to the livestock industry to the tune of several thousand crores of rupees annually. The disease is widely prevalent in India resulting in heavy losses in terms of mortality, morbidity, reduced wool, meat, milk production, reproductive disorders and expenditure on the purchase of antiparasitic drugs. In general, the parasitic diseases cause great economic losses. The total Livestock population is 535.78 million in the country (2019 census) showing an increase of $4.6 \%$ over Livestock Census2012. Total Bovine population (Cattle, Buffalo, Mithun and Yak) is 302.79 million in 2019 which shows an increase of $1.0 \%$ over the previous census. The total number of cattle and buffaloes in the country is 192.49 million and 109.85 million in 2019 showing an increase of 0.8 $\%$ and $1.0 \%$ over previous Census respectively. The total sheep and goats in the country is 74.26 million and 148.88 million in 2019, increased by $14.1 \%$ and $10.1 \%$ over previous Census respectively.It has been estimated that more than 500 million cattle worldwide are at risk (Ristic, 1988). India accounts 51\% of Asia and about $19 \%$ of world bovine population (Kadiravel, 2002). It is assumed that $80 \%$ of Indian herd is within areas endemic for infection.

Paramphistomosis is a group of disease caused by the various species of parasites; Paramphistomum epiclitum, P. cervi, and Gastrothylax crumenifer are found to be predominant in domestic ruminants. The other amphistome species viz. Cotylophoron bareilliensis and $C$. indicum found in sheep, $C$. bareilliensis in goats and P. dutti, Duttielacephaloporus, Olveriabosi and $O$. indica found in buffaloes (Prasad and Verma, 1999). These parasites have complex life cycles and develop through various developmental stages thereby leading to the complexity of their antigenic moieties. These parasites share their antigenic epitopes with each other, which adds to the complexity of cross reactivity. The eggs of these parasites are detected during patent stages because parasites remain attached to their predilection sites of the host. The disease is a major concern in low-lying areas as the snail population viz. Indoplanorbis, Lymnaeaand Gyraulusspp (intermediate host in the life cycle of paramphistome) increases mainly during monsoon and post monsoon season, which is characterized by sporadic epizootics of acute gastroenteritis with high morbidity and mortality in young domestic animals. Immature parasites are predominant in dorsal and ventral sacs of rumen of buffaloes, sheep and goats (Verma et al, 1989). Incidence of amphistomosis in cattle, buffaloes, sheep and goat has been reported in different states of India from time to time (Chhabra et al 1972; Chhabra and Gill, 1975; Gupta et al., 1978; Panda \&Misra, 1980; Varma et al, 1989; Manna et al 1994;Saheb \& Hafeez, 1995 and Magdy et al. 2009). The rate of paramphistomosis incidence was recorded to be highest in buffaloes $5.42 \%$ followed by cattle, sheep and goats in Punjab (Hassan et al, 2005). Dunn (1969) reported most of outbreaks in sheep and goats are due to transmission of infection through bovines. The mortality rate was recorded to be $10-20 \%$ in cattle, $38 \%$ in buffaloes and $80-83 \%$ in goats and sheep. The death rate due to immature paramphistomosis is very high and may go upto $80-90 \%$ in domestic ruminants. Besides chemotherapeutic control of the disease, of late the attention is being laid on the immunological based diagnostic techniques. The early detection of the disease and its diagnosis during sub-clinical phase is of utmost importance so that the mortality can be reduced by timely treatment of the disease. In fact, the use of conventional method to detect light infection during sub-clinical phase is difficult due to prolonged prepatency and non-availability of any parasitic stage during the period making conventional diagnosis difficult or impossible.

The effective control of the disease is possible with integrated programmes that utilize appropriate diagnostic technologies, sound management practice, selective use of drug and effective vaccines. Microscopy although remains the gold standard for detection of parasite but it lacks sensitivity. However many sero-diagnostic tests such as the widely used test i.e., indirect fluorescent antibody test (IFAT), and latest technique ELISA (Enzyme linked Immunosorbent Assay) hold promise. Dot-ELISA is a modified version of the microplate ELISA suitable for field application. ELISA is being practiced as the most effective diagnostic technique for detection of antiparasitic antibodies. The early detection of the disease and its diagnosis during sub-clinical phase is of utmost importance so that the mortality can be reduced by timely treatment of the disease. An attempt has been made in the present work to study the prevalence of paramphistomosis in Punjab by Dot-ELISA technique. Dot-ELISA is a simple, fast, and sensitive test 
recommended for field diagnosis of parasitic diseases like fascioliasis, paragonimosis and haemonchosis (Ibarra et al. 1998 and Zhang et al. 2000).

\section{MATERIALS AND METHODS}

Live flukes were collected from rumen of slaughtered goats, sheep and buffaloes from slaughter houses in Bareilly, Delhi, Dehradun and Ludhiana. The collected parasites were washed thoroughly in normal saline and then stored at $-20 \mathrm{C}$ till further use.

\section{Preparation of Antigen}

The collected parasites were washed thoroughly in normal saline and homogenized in 0.1 M PBS ( $\mathrm{pH} 7.4)$ and sonicated in Soniprep 150 at 10 (amplitude) for 8 min (4 cycles of 2 minute each). The homogenate was then centrifuged at $15000 \mathrm{rpm}$ for $15 \mathrm{~min}$ at $4^{\circ} \mathrm{C}$. The supernatant obtained was filtered through $0.22 \mathrm{~m}$ Millex GV filter and stored in small aliquots of $0.5 \mathrm{ml}$ each at $-20{ }^{\circ} \mathrm{C}$, after protein estimation by Lowry et al (1951). The collected filtrate was used as antigen for immunodiagnostic tests.

\section{Production of Antibodies in rabbits}

The New Zealand white rabbits were acclimatized in the laboratory for 15 days before starting the experiment. They were immunized subcutaneous with $400 \mathrm{~g}$ of P.epiclitumsomatic antigen mixed with Freund's Complete Adjuvant (FCA). This was followed by booster dose of Ag with FIA (Freund's Incomplete Adjuvant) after an interval of 7days and then immunized the rabbit with $400 \mathrm{~g}$ of the antigen alone after an interval of 7 days till desired Ab titre obtained. The animals were bled before starting the experiment for collection of pre-immune sera to be used as control and also before each booster immunization and the serum was refrigerated at $-20{ }^{\circ} \mathrm{C}$ till use.

\section{Production of Antibodies in sheep}

For raising experimentally infected sheep sera, six sheep below one year old were procured. Para Amphistome metacercariae were collected for experimental production of disease in sheep after exposing the snails against artificial light and sunlight. The metacercariae were collected and counted. Of which, 4000 metacercariae were given to four sheep individually for raising paramphistome infection in experimental condition. The animal was starved for 12 hours before giving the infection. Metacercariae was kept in small quantity of water in a glass tube then transferred in glass syringe and poured into the oral cavity. Faecal samples examined microscopically and found positive for paramphistome eggs after 135 days post infection. Serological samples were collected twice in a week for Dot-ELISA immunodiagnostic tests with various kind of paramphistome antigen.

\section{Detection of Antibodies by Dot-Enzyme linked Immunosorbent Assay}

Indirect Dot-ELISA was used for the detection of anti$P$. epiclitum antibodies. The Nitrocellulose membrane (NCM) pad fixed over the combs was used for $P$. epiclitum antigen coating for Dot-ELISA and kept overnight at $4^{\circ} \mathrm{C}$. The combs were incubated in $3 \%$ lactogen in $\mathrm{PBS}, \mathrm{pH}=7.4$, at $37^{\circ} \mathrm{C}$ for $1 \mathrm{~h}$ for blocking the non-specific antigen binding sites and then in rabbit anti-P. epiclitumsera in dilution range 1:50 1:90000 at $37^{\circ} \mathrm{C}$ for $1 \mathrm{~h}$ followed by three washings in PBS of 2 min each. The combs were then incubated in goat anti-rabbit HRPO and bovine anti-rabbit HRPO conjugate at $37^{\circ} \mathrm{C}$ for $1 \mathrm{~h}$ again followed by 4 washings in PBS of 2 min each and then in substrate 3,3'Diamino-benzidine hydrochloride ( $5 \mathrm{mg} / 10 \mathrm{ml}$ PBS + $10 \mu \mathrm{l} 0.06 \% \mathrm{H}_{2} \mathrm{O}_{2}$ ) for 5- $15 \mathrm{~min}$. Development of dark brown spot indicated positive reaction. Various controls (positive and negative) were also included.

Polyclonal antibodies were tested and found positive by Dot-ELISA using P. epiclitumsomatic antigen. The test antigen was diluted to concentration between 10 $\mathrm{g} / \mathrm{l}$ to $10 \mathrm{ng} / \mathrm{l}$. The dilution range of sera was used between $1: 100$ to $1: 80000$.

\section{RESULTS AND DISCUSSION}

\section{Dot-Enzyme Linked Immunosorbant Assay (Dot-ELISA)}

Indirect Dot-ELISA against adult somatic P. epiclitum antigen was performed using 12 leg nitrocellulose membrane pad coated comb ELISA strips with the help of 96 well ELISA microtitre plate (Greiner). DotELISA for paramphistomosis was standardized using the concentration of adult somatic antigen of $P$. epiclitum ranging from $10 \mathrm{ng} / \mu \mathrm{l}$ to $2 \mu \mathrm{g} / \mathrm{ml}$ and goat anti rabbit HRPO conjugate dilution ranging from 1:100 - 1: 5000 and sera dilution ranging from 1:200 $1: 32000$.

The combs were incubated in $3 \%$ lactogen in $0.1 \mathrm{M}$ PBS ( $\mathrm{pH}=7.4$ ) at $37{ }^{\circ} \mathrm{C}$ for $1 \mathrm{hr}$ for blocking the nonspecific binding sites. Subsequently the combs were incubated in rabbit anti-P. epiclitum hyper immune sera in dilution range $1: 50-1: 12800$ at $37^{\circ} \mathrm{C}$ for $1 \mathrm{hr}$ followed by three washings in PBS of two minutes 
each. The combs were then incubated in goat antirabbit HRPO conjugate at $37^{\circ} \mathrm{C}$ for $1 \mathrm{hr}$ again followed by 3 washings in PBS of two minutes each. The combs were then incubated with Diaminobenzidine dihydrochloride (DAB) 25mg/10ml PBS + 10 $\mu \mathrm{l}$ $0.06 \%$ of $\mathrm{H}_{2} \mathrm{O}_{2}$ for $5-15$ minutes. The reaction was stopped with distilled water and dark brown coloured spot developed on the nitrocellulose membrane in the region where antigen was coated (Fig.1). It indicated positive reaction between antigen and antibody. The optimum antigen concentration was found between 50-100ng/ul, anti-rabbit HRPO conjugate concentration at 1:500 and 1:1000 and sera dilution at $1: 400$ to $1: 800$. Antibody titre of rabbit hyperimmune sera of different time interval was also checked and found positive following serial dilutions ranging from $1: 200$ to $1: 12,800$. Anti-P. epiclitum sera dilution from rabbit No. 1and 2 at the interval of 30 days post immunization showed a maximum titre of 1:10,000.

\section{Examination of Experimental Sheep Sera for the Detection of Paramphistmosis}

The experimentally infected sheep sera were taken at weekly interval from six sheep, which were examined against adult somatic $P$. epiclitum antigen following concentrations 50-75 $\mathrm{ng} / \mu \mathrm{l}$ and conjugate dilution 1:500 to $1: 1000$ and sera dilution at $1: 600$ and $1: 800$. Preimmunised and postimmunised anti-P. epiclitum rabbit sera and naturally infected sheep sera were included in the ELISA comb as negative and positive control sera. All four sheep, which were infected with oral inoculation of paramphistomemetacercariae at different, time intervals. Sheep No. 1, 2, 3, 4, and 5 showed reaction after 2 weeks post infection where as sheep No 6 showed reactions after $7^{\text {th }}$ week post infection.

\section{Indirect Dot-ELISA with Clinical/Field Sera}

A total of 200 sera samples (82 sheep, 75 buffaloes, 28 goats and 15 cattle) were examined by indirect DotELISA. Various negative and positive controls were included. Out of the total examined sera 66 samples (29 buffaloes, 26 sheep, 7 goats and 4 cattle) were found to be positive with the incidence rate of $33 \%$. The highest percent positivity (38.66\%) was found in buffaloes followed by $31.7 \%$ in sheep, $26.66 \%$ in cattle and $25 \%$ in goats. The observation for the detection of paramphistome infection in200 clinical/field sera samples by indirect Dot-ELISA is depicted in Table -1 .

Table 1: Paramphistome antibodies detection by Dot-ELISA in field cases.

\begin{tabular}{|l|c|c|c|}
\hline Animal Sera & No. Examined & No. Positive & Percent (\%) positivity \\
\hline Buffaloes & 75 & 29 & 38.66 \\
\hline Cattle & 15 & 4 & 26.66 \\
\hline Sheep & 82 & 26 & 31.7 \\
\hline Goats & 28 & 7 & 25.00 \\
\hline Total & 200 & 66 & 33.0 \\
\hline
\end{tabular}

Various immunodiagnostic techniques are being employed for titre determination like agar gel precipitation test (AGPT), Indirect haemagglutination test (IHA), Conglutinating complement absorption test (CCAT) and ELISA. Among such tests enzyme linked immunesorbent assay (ELISA) has been extensivelyused (Burdenand Hammet, 1978, Farrel, 1981; Zimmerman et al., 1982). ELISA is being practiced as the most effective diagnostic technique for detection of anti-parasitic antibodies. Zimmerman et al. (1985) observed antibodies against crude formulations of excretory-secretory preparations derived from adult Fasciola hepatica at 4 weeks postinfection in sheep using Dot-ELISA. ELISA especially
Dot-ELISA has been observed as a specific and sensitive serodiagnostic method for Paragonimosis sp. (Zhang et al. 2000). It is a fast, simple and inexpensive test and also found suitable for field diagnosis of fasciolosis in cattle. The test showed a sensitivity of $82 \%$, specificity of $90 \%$ with $95 \%$ confidence level (CL), good repeatability and a significant association with reference to ELISA (Maisonnave, 1999). Furthermore in comparison to diffusion in gel (DIG) ELISA and indirect ELISA tests, Dot-ELISA (with sensitivity of $93.1 \%$ and specificity $95.4 \%$ has been found to be highly effective and may be recommended for use in sero-epidemiological surveys of $F$. hepatica (Ibarra et al.1998). ELISA has also been observed to be 


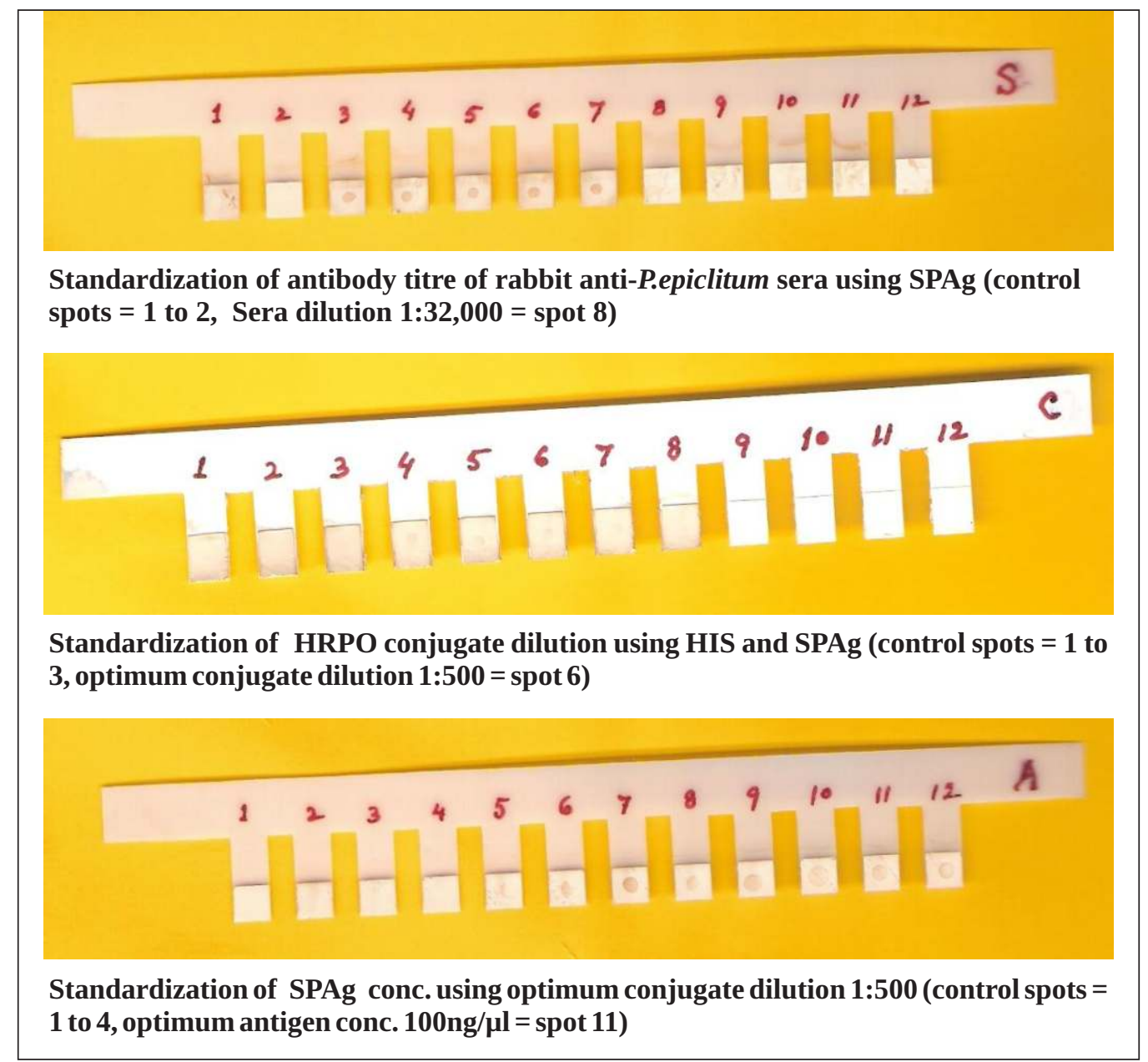

Figure 1: Standardization and Development of Dot-ELISA for the detection of anti-P. epiclitum Antibodies in Ruminants.

suitable for widespread use in the diagnosis of cryptosporidiosis (El-Shazly-AM et al.2002). In Haemonchuscontortus also a high titre of 1:40000 were observed with rabbit hyperimmune sera raised against somatic antigen of $H$. contortus (Kaur et al. 2002a, b). In the present study, prevalence of paramphistomosis by the application of Dot-ELISA technique was recorded to be 31 percent. The highest percent positivity (36.84\%) was found in buffaloes followed by $30 \%$ in sheep, $28.57 \%$ in cattle and $20 \%$ in goats. It may be due to cross reactivity with other metazoan parasites as well as other reason for increased prevalence rates recorded by serological tests (Chan and Ko, 1990).It has been found that false positive and false negative results in other diagnostic assays can often be resolved by immunoblotting (Molina et al. 1993). Percentage prevalence by Dot-
ELISA in different animals revealed that the early diagnosis is very important for curtailing the loss due to disease by appropriate treatment. Hence the high titre observed in the present study may prove to be of great significance in diagnosis of paramphistomosis in field cases for the immunological control of the disease.The application of Dot-ELISA diagnostics against paramphistomosis in domestic ruminants is very sensitive and specific.

\section{CONCLUSION}

Paramphistomosis is a pathogenic disease in domesticated animals causing morbidity and mortality in livestock industry. The control of disease will benefit the farmers in terms of economic status. The sera of anti$P$. epiclitum and experimental sheep can be used as reference sera with paramphistome antigens for 
immunodiagnosis of paramphistomosis. Immature flukes causing paramphistomosis was identified through the dynamics of serodiagnostic tests in domestic animals. Immunodiagnostic tests such as Dot-ELISA are very sensitive tests and useful for the detection of paramphistome antibodies in clinical field cases. These observations are very important for the diagnosis of paramphistomosis and immunological control of the disease occurring in livestock industry. The mortality of animal due to paramphistomosis may be significantly reduced by detecting infection at the earliest.

\section{ACKNOWLEDGEMENTS}

Author is thankful to Science \& Engineering Research Council, Department of Science \& Technology, Ministry of Science \& Technology, Govt. of India New Delhi for financial support in the form of DST-SERCFAST-Track project and Guru Angad Dev Veterinary and Animal Sciences University, Ludhiana, for facilities provided.

\section{REFERENCES}

1. Burden, D. J. and Hammet, N. C. (1978) Microplate enzyme linked immune-sorbent assay for antibodies to Fasciola hepatica in cattle. Vet.Rec., 103:108.

2. Chan. S.W. and Ko, P.C. (1990) Cross reaction between crude antigens of Trichinella spiralis and nematodes of Chinese pigs. Trop. Biomed., 7: $143-150$

3. Chhabra, R. C., Kwatra, M. S. and Bali, H. S. (1972) Immature paramphistomiasis in Sahiwal and crossbred calves in Punjab. Indian Journal of Animal Sciences, 42 (4), 272-74.

4. Chhabra, R. C. and Gill, B. S. (1975) Incidence of helminthic infections and control of amphistomiasis and fascioliasis in animals in two villages of the Punjab. Journal of Research, PAU, $12,184-188$

5. Dunn, M. A. (1969) Veterinary Helminthology. William Heinemann Medical Books Ltd., London pp.165.

6. El-Shazly, A.M., Gabr-A., Mahmoud, M.S.E., Aziz-S.S. A and Saleh, W.A. (2002) The use of Ziehlneelsen stain, ELISA and nested PCR in diagnosis of cryptosporidiosis in immunocompetent - compromised patients. Journal of Egyptian Society of Parasitology, 32 (1) $155-166$.
7. Farrel, C.J., Shen, D.T., Wescott, R.B. and Lang, B.Z. (1981) An enzyme linked immunesorbent assay for diagnosis of Fasciola hepatica infections in cattle. Am. J. Vet. Res., 42: 237.

8. Gupta, P. P., Balwant Singh and Dutt, S. C. (1978) A note on amphistomiasis in an adult. Buffalo. Indian Veterinary Journal, 55, 491-92.

9. Hassan, S. S., Kaur, K., Joshi K. and Juyal P. D. (2005) Epidemiology of paramphistomosis in domestic ruminants in different district of Punjab and other adjoining areas. Journal of Veterinary Parasitology, 19 (1), 43-46.

10. Ibarra, F., Montenegro, N., Vera, Y., Boulard, C., Quiroz, H., Flores, J and Ochoa, P. (1998) Comparisonof three ELISA tests for seroepidemiology of bovine fasciolosis. Veterinary Parasitology, 77 (4) 229-236.

11. Kadiravel, R. (2002) Limited investment but consistent growth. In: Survey of Indian Agriculture, The Hindu, Kasthuri publications, Chennai, pp.147-150.

12. Kaur, K., Kapur, J., Parmar, A. and Sood, M. L. (2002a) Kinetics of antibody response by Dot ELISA in rabbits immunized with adult Haemonchuscontortus antigen. Parasite, 9, $363-$ 365.

13. Kaur, K., Kapur, J., Parmar, A. and Sood, M. L. (2002b) Identification of immunodominant antigen of adult Haemonchuscontortus (Nematoda: Trichostrongylidae). J. Vet. Med., B 49, 260-262.

14. Lowry, O. H., Rosbrought, N. J., Farr, A. L. and Randall, R. J. (1951) Protein measurement with the folin phenol reagent. J. Biol. Chem., 193, 265275.

15. Magdy H. Al-Gaabary, Salama A. Osman and Amera G.M. El-Tonoby (2009) Studies on paramphistomiasis in ruminants. Kafrelsheikh, Vet. Med. J., 3rd Sci. Congress. 10-12 May 2009, pp.116-136.

16. Manna, A. K., Pramanik, S. and Mukherjee G. S. (1994) Incidence of Paramphistomosis in West Bengal. Indian Journal of Animal Health, 33 (2), 87-89.

17. Maisonnave, J. (1999) Standardization of a dot immunoperoxidase assay for field diagnosis of 
Fasciola hepatica infected cattle. Veterinary Parasitology, 85 (4) 259-268.

18. Molina Caballero J. M., Anguiano, A., Ferrer, O., Serrano, E. and Ueeda, A. (1993) Use of an enzyme linked immuno sorbent assay for serodiagnosis of clinical paratuberculosis in goats: study by western blotting of false positive reactions. Rev. Sa. Tech. Off. Int. Epiz., 12, 629638.

19. Panda, B. K. and Misra, S. C. (1980) Observations on the etiology, clinical pathology and chemotherapy of immature amphistomiasis in buffalo calves. Indian Journal of Animal Health, 29, a 2,131-35.

20. Parsad, A. and Varma, T. K. (1999) On the prevalence and community dominance among paramphistomes infecting domestic ruminants. Journal of Veterinary Parasitology, 13 (2), 129 133.

21. Ristic (1988) Babesiosis of domestic animals and man, CRC Press Boca, Raqton, Florida, pp. 1-227.

22. Saheb, S. R. and Hafeez, M. (1995) Haematological changes in buffaloes infected with amphistomiasis. Buffalo Bulletin, 14 (3), 55-57.
23. Santra, A. K. and Pachalag, S. V. (1996) Mortality pattern in crossbred calves. Indian Journal ofAnimal Sciences, 66 (3), 237-38.

24. Singh, P., Sisodia, B. V. S. and Kunzru, O. N. (1983). Effects of seasons on economic losses due to livestock diseases. Ann. Agric. Res. 4 (1-2), 7580.

25. Varma, T. K., Prasad, A., Malviya, H. C. and Dwivedi, P. (1989) Incidence of paramphistome infections in ruminants at Bareilly. Indian Journal of Animal Sciences, 59 (2), 231-234.

26. Zhang, X. L., Duan, J. H., Wang, Y., Kuang, M. S. and Huang, P. S. (2000) Analysis of Paragonimusskrjabiniantigen and its application in serodiagnosis. Chinese Journal of Parasitology and Parasitic Diseases, 18 (5): 277-281.

27. Zimmerman, G.L., Hjen, L. W., Cerro, J.W., Farasworth, B.S. and Wescott, R.B. (1982) Diagnosis of Fasciola hepatica infection in sheep by ELISA. Am. J. Vet. Res., 43: 2097-2100.

28. Zimmerman, G.L., Nelson, N. L. and Clark, C.R.B. (1985) Diagnosis of ovine fasciolosis by Dot-ELISA- A rapid diagnostic technique. Am. J. Vet. Res., 43: 1513-1515. 